\title{
A Novel Global Warming Solution: Use of Flue Gas to Produce Urea
}

\author{
Zaina AIDhaheri, Saniha Aysha Ajish,Sumaita Rahman, Laila Owda, Salma AINowahi, Omar Chaalal \\ College of Engineering, Chemical Engineering Department, Abu Dhabi University UAE
}

\begin{abstract}
Urea is a nitrogenous organic compound which is widely used as a fertilizer and in the agricultural industry. On an industrial scale, urea can be manufactured from the reaction of carbon dioxide and ammonia. The goal of this research is to design a plant that produces $46.84 \mathrm{tons} / \mathrm{hr}$ of urea from the raw materials carbon dioxide and ammonia. The quantities of carbon dioxide and ammonia consumed in the process were $37.32 \mathrm{tons} / \mathrm{hr}$ and 28.84 tons $/ \mathrm{hr}$, respectively. The carbon dioxide is obtained using a sustainable approach from the waste products, the flue gas, of a nearby power plant. In the first step of the process, carbon dioxide is extracted in an absorption column that uses ammonia and stripping columns from the flue gases emitted from a power plant. This ensures that the whole production process is environmentally sustainable and contributes to the reduction of carbon dioxide that cause global warming.
\end{abstract}

\section{Introduction}

Carbon dioxide is the main greenhouse gas that needs to be reduced from the atmosphere. There are various technologies used to separate $\mathrm{CO}_{2}$ from flue gas. These include chemical solvent methods, physical absorption methods, cryogenic methods, membrane systems, biological fixation, and $\mathrm{O}_{2} / \mathrm{CO}_{2}$ combustion process. Compared to the chemical plant, power plant has a large flue gas flow, different ingredients, relatively low $\mathrm{CO}_{2}$ concentration and other characteristics. The chemical solvent techniques are generally recognized as the most effective technologies for $\mathrm{CO}_{2}$ removal. This requires that the researchers developed a relatively low-cost, lowenergy requirement $\mathrm{CO}_{2}$ capture technology. Among the conventional $\mathrm{CO}_{2}$ chemical removal processes, the monoethanolamine (MEA) process has been comprehensively studied and successfully used in chemical plants for $\mathrm{CO}_{2}$ recovery in natural gas processing. Although the MEA process is a promising system for the control of $\mathrm{CO}_{2}$

\section{Urea around the globe}

Urea is one of the most demanded chemical around the globe because it increases the yield of the crops which help meet the demand of adequate nourishment of the human race. Urea is most manufactured in China, where the production of urea has been over 60 million tons since 2013. India is the 2 nd largest producer of urea around the globe. It manufactures about 20 million tons of urea annually from the year 2000 as of 2016, but the production of urea is expected to slightly decline by the year 2021 [5].

\subsection{Urea in GCC}

Middle East is the 3rd largest to manufacture urea annually [6]. It produced around 20 million tons of urea in the year 2015 and 2016 which is $100 \%$ increase from what it used to produce in the year 2000, and accounts for $39 \%$ of the world export. Due to the abundance of the raw materials in the Middle East, it takes only 100 dollars per ton to produce urea compared to United States, Russia, and China who need over 150 dollars per ton to produce urea $[5,6]$. The largest producers of urea in Middle East are Qatar, Saudi Arabia, and Iran. Qatar produced over 5 million tons of urea according to a data in 2013. On the other hand, Saudi Arabia, who is also the largest urea producer in GCC, has produced around 3.5 million tons of urea in 2013 [6]. The other GCC countries that produce urea in decreasing rate are United Arab Emirates, Oman, Kuwait, and Bahrain respectively [7].

\subsection{Saudi Arabia}

Saudi Arabia manufactures the largest quantities of urea and fertilizers in GCC. The production capacity of this country accounts for $36 \%$ of GCCs' total fertilizer industry. It reached about 10.9 million tons in 2012. This has been majorly contributed by Ma'aden Phosphate Company's Fertilizer Complex [7] "With the launch of Safco 5 this year, notable for possessing one of the world's largest carbon capture units, and Maaden's Waad Al Shamal phosphates facility in 2016, Saudi fertilizers will continue to see much dynamism in the near future," continued Dr. Al- Sadoun [8]. 


\subsection{United Arab Emirates}

The 2nd largest producer of urea in GCC is United Arab Emirates, which produced around 1.5 million tons of urea in the year of 2013 [6]. There are a handful of companies that produce like ADFERT, Prompt Point fze, and FERTIL (largest urea producing company in UAE) [9]. FERTIL is a joint venture between ADNOC, with $66.6 \%$ of stake, and French oil and gas major Total, with the remaining $33.4 \%$ of the stake [10]. FERTIL produces 450,000 tons per annum ammonia of which 350,000 tons per annum is utilized for the production of urea. "Fertil's yearly exports currently stand at 100,000 tpa of liquid ammonia and more than 625,000 tpa of urea (bulk and bagged)," said Yousef Omeir Bin Yousef, CEO of Adnoc [11]. This project has commissioned to expand their project to FERTIL-2, which was built at the cost of 1.2 billion dollars. FERTL-2 can produce 3,500 tons/day of urea at fullest capacity, which has greatly boosted the production of urea in UAE [10]. FERTIL exports majority of their manufacture to foreign countries like Brazil, Pakistan, Australia, and the United States [10, 12].

\section{Carbon dioxide affects global warming}

Since 1988, the world's environmental scientists on the Intergovernmental Panel on Climate Change (IPCC, 2014) have provided multiple and clear scientific reports on the state of knowledge on climate change. It is an undeniable fact that our planet is warming and the climate is changing. Because of the impact of global warming on our future, it is the most important environmental issue and a subject of actuality in present. For instance, extreme weather disasters have partially or completely damaged crop production in many parts of the world [13-17].

Global warming is the gradual noticeable increase in the earth's average overall temperature due to the earth's heat being trapped in the atmosphere. It is mainly caused by the greenhouse effect. One of the main gases that cause global warming is carbon dioxide. Carbon dioxide is either released into the atmosphere by natural processes like volcanic eruptions and naturally accruing fires or by human processes like the burning of fossil fuels leading to very drastic effects on the environment [18]. Power plants, oil refineries, and other factories produce $\mathrm{CO}_{2}$ in large quantities which is beyond the earth's capacity to absorb and neutralize. Mainly in GCC countries, where the demand for desalinated water is high, the emissions of carbon dioxide are increasing rapidly. In order to decrease those environmental effects, the plant presented in this study will reuse the carbon dioxide from power plants in desalination plants in production of urea. This will reduce the overall amount of carbon dioxide emitted into the atmosphere and the plant will save up costs of producing or extracting carbon dioxide in order to be used. Recent project was studied to reduce $\mathrm{CO}_{2}$ from either natural gas or exhaust gases where the experimental results showed excellent removal of $\mathrm{CO}_{2}$ [19-21]. There are several ways to reduce carbon dioxide while making good use of it when dealing with reactions such as the production of urea. Moreover, putting the environmental effects under consideration while making a plant will help to reduce the effects of global warming which vary from increase of global temperature and sea levels to rough heat waves and intense hurricanes [22, 23].

\section{Theory of the process: Ammonia and $\mathrm{CO}_{2}$ Reactions}

The commercial synthesis of urea involves the combination of ammonia and carbon dioxide at high pressure to form ammonium carbamate which is subsequently dehydrated by the application of heat to form urea and water. $\mathrm{NH} 3$ and $\mathrm{CO} 2$ are converted to urea via ammonium carbamate at a pressure of approximately $140 \mathrm{bar}$ and a temperature of $180-185^{\circ} \mathrm{C}$.

\section{Ammonium carbamate}

$$
2 \mathrm{NH}_{3}(\mathrm{~g})+\mathrm{CO}_{2}(\mathrm{~g}) \rightleftarrows \mathrm{NH}_{2} \mathrm{COONH}_{4}(\mathrm{~s})
$$

\section{Urea}

$$
\mathrm{NH}_{2} \mathrm{COONH}_{4} \rightleftarrows \mathrm{NH}_{2} \mathrm{CONH}_{2}(\mathrm{l})+\mathrm{H}_{2} \mathrm{O}(\mathrm{g})
$$

Equation 1 is fast and exothermic and essentially goes to completion under the reaction conditions used industrially. Equation 2 is slow, endothermic, and does not achieve full conversion (about $50-80 \%$ on $\mathrm{CO}_{2}$ basis). The conversion can be increased by increasing the temperature and the $\mathrm{NH}_{3} / \mathrm{CO}_{2}$ ratio, however, it decreases with increasing $\mathrm{H}_{2} \mathrm{O} / \mathrm{CO}_{2}$ ratio.

The total reaction of aqueous ammonia absorb carbon dioxide can be described as in Equation 1:

$$
\mathrm{CO}_{2}(\mathrm{~g})+\mathrm{NH}_{3}(\mathrm{aq})+\mathrm{H}_{2} \mathrm{O}(\mathrm{l}) \rightleftarrows \mathrm{NH}_{4} \mathrm{HCO}_{3}(\mathrm{aq})
$$

The actual process of the reaction is more omplicated, which can be described as step-by-step reactions.

First of all, in Equation 2, $\mathrm{CO}_{2}$ and $\mathrm{NH}_{3}$ react to generate $\mathrm{NH}_{2} \mathrm{COONH}_{4}$, then $\mathrm{NH}_{2} \mathrm{COONH}_{4}$ hydrolyzes in solution instantaneously.

$\mathrm{CO}_{2}(\mathrm{~g})+2 \mathrm{NH}_{3}(\mathrm{aq}) \rightarrow \mathrm{NH}_{2} \mathrm{COO}-(\mathrm{aq})+\mathrm{NH}_{4}+(\mathrm{aq})$

Then, $\mathrm{NH}_{4}+$ and $\mathrm{NH}_{2} \mathrm{COO}$ - have an irreversible reaction (Equation 3 ) in solution:

$$
\mathrm{NH}_{2} \mathrm{COO}-(\mathrm{aq})+\mathrm{NH}_{4}+(\mathrm{aq})+2 \mathrm{H} 2 \mathrm{O} \rightarrow
$$$$
\mathrm{NH}_{4} \mathrm{HCO}_{3}(\mathrm{aq})+\mathrm{NH}_{3}(\mathrm{~g})+\mathrm{H}_{2} \mathrm{O}(\mathrm{aq})
$$

At the same time, the complex balances of solute ionizing and ion reactions are happening in the solution shown below:

$$
\begin{aligned}
& \mathrm{NH}_{3}(\mathrm{aq})+\mathrm{H}_{2} \mathrm{O}(\mathrm{l}) \underset{\mathrm{NH}_{4}+(\mathrm{aq})+\mathrm{OH}-(\mathrm{aq})}{\rightleftarrows} \mathrm{NH}_{4} \mathrm{HCO}_{3}(\mathrm{aq}) \stackrel{\mathrm{NH}_{4}+(\mathrm{aq})+\mathrm{HCO}_{3}-(\mathrm{aq})}{\rightleftarrows}
\end{aligned}
$$$$
\text { [Equation 7] }
$$$$
(\mathrm{NH} 4)_{2} \mathrm{CO}_{3}(\mathrm{aq}) \rightleftarrows 2 \mathrm{NH}_{4}+(\mathrm{aq})+\mathrm{CO} 32+(\mathrm{aq})
$$

[Equation 8]

$$
\begin{aligned}
& \mathrm{OH}-(\mathrm{aq})+\mathrm{HCO}_{3}-(\mathrm{aq}) \rightleftarrows \mathrm{CO} 32-(\mathrm{aq})+\mathrm{H}_{2} \mathrm{O}(9) \\
& \mathrm{CO} 32-(\mathrm{aq})+\mathrm{CO}_{2}(\mathrm{~g})+\mathrm{H}_{2} \mathrm{O}(\mathrm{l}) \rightleftarrows 2 \mathrm{HCO} \quad(10)
\end{aligned}
$$

Presentation of the process:

The proposed process is done in two steps and the whole process is presented in Figure 1. 


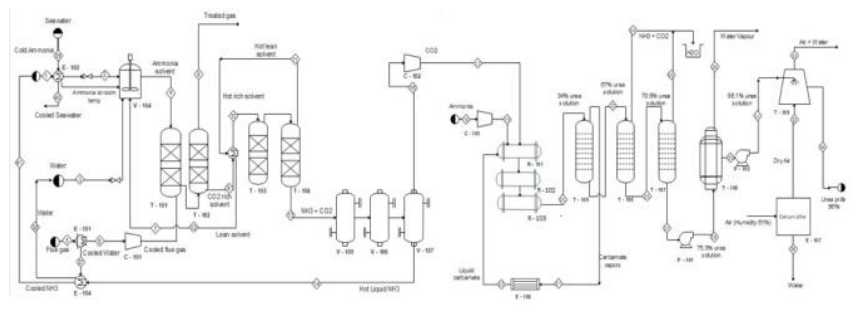

Figure 1. Overall process flow diagram Step 1.

\section{Step 1: Carbon dioxide capture and separation}

The first step of the process, which is the sustainable approach, in this project is to isolate carbon dioxide gas from the flue gases emitted from a nearby power plant, which is done by absorption using ammonia solvent. In order to prepare the ammonia solvent, liquid ammonia is purchased from a supplier and stored in the vicinity of the plant. A valve controls the flow of this liquid ammonia to a mixer where water is also added to make a $30 \%$ ammonia solution to be used as a solvent. Since the temperature of the stored ammonia is extremely low, it is made to pass through a heat exchanger initially where the temperature is raised to room temperature.

The hot flue gas obtained from the nearby power plant cannot be used at high temperatures. In order to bring down the temperature, it is passed through a cooler where the water vapor gets condensed and is recycled back to the water source to prepare the ammonia solution. Once the gasses are cooled, a blower push them to an absorption column that operates at atmospheric pressure and normal temperature.

In the absorption column, the flue gas enters from the bottom and the ammonia solvent enters from the top. The flow is countercurrent where the treated gas, mainly nitrogen, is left to the atmosphere while the carbon dioxide rich solvent is made to enter a heat exchanger. Once the carbon dioxide rich solvent gets heated, it is made to enter a regenerator where two outlet streams are obtained: hot lean solvent and another containing ammonia and carbon dioxide.

In order to obtain the carbon dioxide alone, the former outlet stream from the regenerator is sent to a liquid separator where the carbon dioxide rises to the top of the column and exits out. It is then directed to the second step of the process to be used for urea manufacture. The ammonia liquid which exits from the bottom of the separator gets recycled back to the mixer to make more of the ammonia solvent to be used for absorption. It is important be note that once the process reached steady state, the valve that controls flow of ammonia from the storage tank is closed so that the ammonia solvent keeps getting recycled in the closed loop. This ensures that the process is more profitable and sustainable.

\section{Step 2: Production of urea}

The second part of the process is to actually manufacture the urea. This occurs in a reactor which is at high temperature and high pressure ensuring maximum conversion of the reactants. The reactants used will be the carbon dioxide obtained from the previous process as well ammonia gas which is pumped into the reactor. The end of the reaction shows that $34 \%$ urea solution is produced along with other undesired products such as water, ammonia and carbamate. In order to purify the urea more, it sent to a stripping column where the carbamate separates out from overhead, The carbamate is then sent to a carbamate condenser where it is condensed back to liquid from and then recycled back to the reactor.

The rest of the $67 \%$ urea solution is sent to a decomposer at medium pressure. Here, $50 \%$ of the undesired ammonia and carbon dioxide gases are removed from the top while giving $70.9 \%$ pure urea solution. This is then sent to another decomposer at low pressure where the rest of the ammonia and carbon dioxide are removed and the only remaining solution $75.3 \%$ urea.

In order to remove the water from this solution, it is sent to an evaporator at vacuum conditions and low pressure, where water gets evaporated and is let into the atmosphere. The remaining $95.1 \%$ urea solution is sent to a prilling tower to further remove moisture content.

In the prilling tower, dry air is required to carry out the process. This dry air is obtained after passing humid air to a dehumidification unit. The urea solution is sprayed in the prilling tower where it counteracts with the dry air to form urea prills of $96 \%$ purity. This is the end product of the urea manufacture which can then later be stored and sold.

\section{Conclusion}

The research in this paper has been developed using the most practical but cost efficient and sustainable measures to produce urea. One of the main reactants needed for this production, carbon dioxide is obtained through an environment friendly approach. Being located next to a power plant, waste flue gases rich in carbon dioxide can easily be collected and used to produce urea. Using this innovative technique, carbon dioxide gas is obtained from the waste product which would have otherwise been emitted into the atmosphere to cause global warming. The flue gases undergo a series of absorption and regeneration processes with ammonia solvent to get the pure carbon dioxide. The urea is manufactured using this innovative process to get the final commercial product solid urea prills. The whole process has been developed using the most efficient sustainable approach.

\section{References}

1. Chakma, A. "Separation of $\mathrm{CO}_{2}$ and $\mathrm{SO}_{2}$ from Flue Gas Streams by Liquid Membranes". Energy Convers. Manage. 1995, 36, 405.

2. Molburg, J. C.; Thimmapuram, P.; Doctor, R. D. Comparison of Salient Features of Alternatives $\mathrm{CO}_{2}$ Recovery Processes. A\&WMA Annual Meeting, Cincinnati, June 1994; Paper 94-RA113.02.

3. Zhiming Zhang et al., "Research on Physical Chemistry Characters and Production Increasing 
Mechanism of Long Effective Ammonium Bicarbonate" China Science (B), 26, 453 (1996)

4. Bai HL et al., Removal of $\mathrm{CO}_{2}$ Greenhouse Gas by Ammonia Scrubbing, Ind Eng Chem Res, 36, 2490 (1997)

5. Y. Yamaguchi, "A world awash in urea", in 32nd Annual World Petrochemical Conference, 2017.

6. "Home - Industry Overview - PotashCorp", Potashcorp.com, 2017. [Online]. Available: http://www.potashcorp.com/overview/nutrients/nitro gen/overview/global-urea-profile. [Accessed: 23Oct-2017].

7. $2017 . \quad$ [Online]. Available: http://www.gpca.org.ae/ff2012/53.pdf. [Accessed: 23- Oct- 2017].

8. "GCC fertilizer industry more than doubles in the last decade, says GPCA", Gulf Petrochemicals \& Chemicals Association, 2017. [Online]. Available: http://www.gpca.org.ae/news/gcc-fertilizer-industrymore-than-doubles-in-the-last-decade-says-gpca/. [Accessed: 23- Oct- 2017].

9. "List of Urea Fertilizer companies in United Arab Emirates", Listofcompaniesin.com, 2017. [Online]. Available: http://www.listofcompaniesin.com/unitedarab-emirates/urea-fertilizer/. [Accessed: 24- Oct2017].

10. D. Thapliyal, "UAE\&\#39;s FERTIL to start urea, ammonia production at new plant in June", Icis.com, 2013. [Online]. Available: https://www.icis.com/resources/news/2013/05/13/96 67976/uae-s-fertil-to-start-urea-ammonia-productionat-new-plant-in-june/. [Accessed: 24- Oct- 2017].

11. S. Carvalho, "Fertil joins hands with France's Total to enhance urea production capacity", Gulf News, 2006.

12."2013 Minerals Yearbook", 2015. [Online]. Available: https://minerals.usgs.gov/minerals/pubs/country/201 3/myb3-2013-ae.pdf. [Accessed: 24- Oct- 2017].

13. Battisti, D. S. \& Naylor, R. L. Historical warnings of future food insecurity with unprecedented seasonal heat. Science 323, 240-244 (2009)

14. World Food Program . Pakistan - Flood Impact Assessment http://documents.wfp.org/stellent/groups/public/docu ments/ena/wfp225987.pdf (2010)

15. Gu, L. et al. The 2007 eastern US spring freeze: increased cold damage in a warming world. Bioscience 58, 253 (2008)
16. Barriopedro, D., Fischer, E. M., Luterbacher, J., Trigo, R. M. \& García-Herrera, R. The hot summer of 2010: redrawing the temperature record map of Europe. Science 332, 220-224 (2011)

17. Coumou, D. \& Rahmstorf, S. A decade of weather extremes. Nature Clim. Change 2, 491-496 (2012).

18. "Cite a Website - Cite This For Me", Climate.nasa.gov, 2017. [Online]. Available: https://climate.nasa.gov/effects/. [Accessed: 22- Oct2017].

19. O. Chaalal and M. Hossain, "A two-step process for removal of carbon dioxide and production of desalinated water using ammoniated saline water," Environmental Progress \& Sustainable Energy Volume 35, Issue 1, Version of Record online: 3 JUL 2015.

20. Hameed Muhamad and Omar Chaalal "Optimization Study for Carbon Dioxide in flue gas using liquid Membrane Permeator". International Conference: The 9th Dynamical Systems \& Applications July 20-23, 2016 Antalya, Turkey

21. Omar Chaalal, Hameed Muhamad, Md Monwar Hossain and Dalila Hank "A numerical study in a carbon dioxide membrane permeator “ Far East Journal of Mathematical Sciences (FJMS) Volume 99, Issue 12, Pages 1833 - 1847 (June 2016)

22. "Global Warming Effects", Nationalgeographic.com, 2017. [Online]. Available: https://www.nationalgeographic.com/environment/gl obal-warming/global-warming-effects/. [Accessed: 22- Oct- 2017].

23. R. Jackson, "Global Climate Change: Effects", Climate Change: Vital Signs of the Planet, 2017. [Online]. Available: https://climate.nasa.gov/effects/. [Accessed: 22- Oct- 2017]. 